\title{
DESIGN OF FOUR-CAVITY HIGH POWER GYROKLYSTRON AMPLIFIER*
}

\author{
I. Yovchev $^{\#+}$, W. Lawson, M. Castle, G. Nusinovich, V. Granatstein, and M. Reiser, \\ University of Maryland, College Park, MD 20742, USA
}

\begin{abstract}
In order to develop a high power Ku-band gyroklystron amplifier with high gain and efficiency for driving future linear colliders, a theoretical design of a four-cavity coaxial $17.1 \mathrm{GHz}$ gyroklystron amplifier has been carried out. The $\mathrm{X}$-band input cavity operates at $\mathrm{TE}_{011}$ mode while the remaining three cavities (buncher, penultimate and output) operate at $\mathrm{TE}_{021}$ mode, doubling the frequency of the input signal. The simulations show that both a very high efficiency of $45.6 \%$ and a gain of $71 \mathrm{~dB}$ can be realized using a $500 \mathrm{kV}, 700$ A electron beam with a perpendicular-to-parallel velocity ratio of 1.5 and a parallel velocity spread of $6.4 \%$.
\end{abstract}

\section{INTRODUCTION}

Relativistic klystrons, gyroklystrons, magnicons and free-electron lasers are considered as the most promising candidates for driving future linear colliders. For TEVscale linear colliders it is desirable to increase the electric field gradients which can be attained by increasing the radiation frequency. In recent experiments with a three cavity 1-1-1 coaxial gyroklystron carried out at the University of Maryland very high peak microwave powers of $75-85 \mathrm{MW}$ at $8.6 \mathrm{GHz}$ frequency were obtained [1]. The sequence 1-1-1 means that all three cavities, input, buncher and output, operate at the fundamental electron cyclotron frequency, so 1 is the cyclotron resonance harmonic number. To increase the frequency, the output cavity can be designed for operation at the second harmonic.

In previous computer simulations two-cavity and three-cavity frequency doubling gyroklystrons were studied (1-2 and 1-2-2 circuits) [2]. It was shown that introducing a second harmonic buncher cavity into a two-cavity 1-2 circuit (in this way a 1-2-2 circuit can be obtained) may increase the efficiency from $30 \%$ to $41 \%$ and gain from $26 \mathrm{~dB}$ to $49 \mathrm{~dB}$; these results were obtained for a $500 \mathrm{kV}, 700$ A electron beam with a perpendicular-to-parallel velocity ratio (pitch-ratio) $\alpha$ of 1.508 and a parallel velocity spread of $6.4 \%$.

"Work supported by the Department of Energy, Contract DE-FG0294ER40855.

"Email: igy@glue.umd.edu

${ }^{+}$On leave from the Dept. of Physics, University of Chemical Technology and Metallurgy, Sofia, Bulgaria.
To improve the device performance further we have undertaken a design of a four-cavity circuit, using the same beam parameters.

\section{RESULTS FROM A POINT-GAP MODEL OF A FOUR-CAVITY GYROKLYSTRON}

There exist at least four possible schemes of a fourcavity gyroklystron in which the input cavity operates at the fundamental and the output cavity - at the second cyclotron harmonic: 1-1-1-2, 1-1-2-2, 1-2-1-2 and 1-2-22 . Here we may also add the scheme 1-2-4-2 where the third cavity resonates at the fourth harmonic frequency.

The design of each of these possible circuits requires a large consumption of computer time. In order to save this time we have first used a point-gap model (PGM) of the gyroklystron [3] to qualitatively estimate the performance of the five schemes. The PGM implies that the cavities lengths are much shorter than the drift spaces, thus electrons' energy is modulated in each cavity and this modulation causes electron phase bunching in drift regions. The three-cavity gyroklystron PGM developed in [3] was generalized for a four-cavity gyroklystron. The corresponding maximum efficiencies for the five schemes are given in Table 1. These values characterize the efficiency of electron bunching only but not the overall efficiency of the device. It is seen that the 1-2-2-2 circuit is the most efficient. Therefore detailed computer simulations were performed for this circuit.

Table 1: Maximum efficiencies calculated in the framework of PGM for 5 different circuits.

\begin{tabular}{|c|c|}
\hline Circuit & Efficiency (\%) \\
\hline $1-1-1-2$ & 60.0 \\
\hline $1-1-2-2$ & 51.0 \\
\hline $1-2-1-2$ & 66.5 \\
\hline $1-2-2-2$ & 76.0 \\
\hline $1-2-4-2$ & 54.3 \\
\hline
\end{tabular}

\section{DESIGN OF 1-2-2-2 CIRCUIT}

Our 1-2-2-2 circuit was based on the previously optimized 1-2-2 design [2]. The modification was done by inserting before the output cavity a second buncher (or penultimate) cavity with the same dimensions as the first buncher cavity. The geometry of the four-cavity 
system is shown in Fig. 1 and dimensions are tabulated in Table 2.

\begin{tabular}{|c|c|c|c|c|c|c|c|c|}
\hline & \multicolumn{2}{|c|}{ Input } & \multicolumn{2}{|c|}{ Buncher } & \multicolumn{2}{|c|}{ Penultimate } & \multicolumn{2}{|c|}{ Output } \\
\hline 1 & 2 & 3 & 4 & 5 & 6 & 7 & 8 & 910 \\
\hline & & Drift1 & & Drift2 & & Drift3 & & \\
\hline
\end{tabular}

Figure 1: Geometry of the four-cavity 1-2-2-2 circuit

The operating modes are the $\mathrm{TE}_{011}$ mode for the input cavity and $\mathrm{TE}_{021}$ mode for the remaining three cavities. For operation in the $17.1 \mathrm{GHz}$ frequency range, based on previous studies of a 1-2-2 design, the resonant frequencies of the input, buncher, penultimate and output cavities calculated by the scattering matrix code COAX [4,5] are $8.567 \mathrm{GHz}, 17.136 \mathrm{GHz}, 17.136 \mathrm{GHz}$ and $17.063 \mathrm{GHz}$, respectively.

The large-signal code GYCOAX [6] was used for optimization of parameters to get maximum efficiency and gain. In the case of a four-cavity gyroklystron it means a search in a 7-dimensional parameter space: 4 amplitudes $\left(\mathrm{a}_{1}, \mathrm{a}_{2}, \mathrm{a}_{3}\right.$ and $\left.\mathrm{a}_{4}\right)$ and three relative phases $\left(\varphi_{2}, \varphi_{3}\right.$ and $\left.\varphi_{4}\right)$ of the fields in each cavity - the phase $\varphi_{1}$ in the input cavity can be set to 0 without loss of generality.

Table 2: Dimensions of the four-cavity 1-2-2-2 circuit

\begin{tabular}{|l|c|c|c|c|}
\hline $\begin{array}{l}\text { Cavity or } \\
\text { Section }\end{array}$ & No. & $\begin{array}{c}\text { Inner } \\
\text { Radius } \\
(\mathrm{cm})\end{array}$ & $\begin{array}{c}\text { Outer } \\
\text { Radius } \\
(\mathrm{cm})\end{array}$ & Length \\
$(\mathrm{cm})$ \\
\hline Inlet & 1 & 1.825 & 3.325 & 5.000 \\
\hline Input & 2 & 1.100 & 3.325 & 2.286 \\
\hline Drift 1 & 3 & 1.825 & 3.325 & 3.328 \\
\hline Buncher & 4 & 1.610 & 3.520 & 1.691 \\
\hline Drift 2 & 5 & 1.825 & 3.325 & 3.328 \\
\hline Penultimate & 6 & 1.610 & 3.520 & 1.691 \\
\hline Drift 3 & 7 & 1.825 & 3.325 & 3.328 \\
\hline Output & 8 & 1.620 & 3.520 & 1.712 \\
\hline Output & 9 & 1.760 & 3.360 & 0.693 \\
\hline Outlet & 10 & 1.400 & 3.550 & 5.000 \\
\hline
\end{tabular}

Exploration of such a multidimensional space is almost hopeless without certain optimization procedure. For this reason a subroutine which varies all a's and $\varphi$ 's according to the Hooke-Jeeves method [7] and looks for the maximum efficiency was written and successfully embedded into the code GYCOAX. A further improvement of the optimization procedure was made by incorporating in the subroutine additional 3 parameters $I_{1}, I_{2}$ and $I_{3}$, which correspond to the currents in three sets of coils creating the guide magnetic field. Thus, the parametric space becomes 10-dimensional. In this way, however, we merge into one optimization procedure two previously separate procedures: first, optimization of the a's and $\varphi$ 's and second, optimization of the guide magnetic field.

The improved large-signal code was first applied to the configuration, presented in Fig. 1 where all drift spaces have the same length $-3.328 \mathrm{~cm}$ (see also Table 2 ). Both very high efficiency of $43.2 \%$ and gain of 71 $\mathrm{dB}$ were calculated (compare with $41.1 \%$ and $49 \mathrm{~dB}$ for the three-cavity 1-2-2 gyroklystron design [2]).

Additional simulations were performed to further increase the efficiency by: 1) optimizing the drift space lengths and 2) stagger tuning (ST) [8,9] of the last two cavities.

At the first step, there exists an experimental setup constraint: the distance between the input cavity exit and the output cavity entrance have to be kept constant. For that reason, only the buncher and the penultimate cavities were moved. The results are presented in Table 3. In its first two rows 0 means that the cavity is in the same position as in Fig. 1, while +1 or -1 means that the corresponding cavity is displaced by $1 \mathrm{~cm}$ on the right or on the left, respectively. The efficiency for each configuration is given in the last row. The best result is obtained when the buncher cavity position is unchanged while the penultimate cavity is displaced $1 \mathrm{~cm}$ on the right (see fifth column in Table 3). For all five considered cases the gain is approximately $71 \mathrm{~dB}$.

Table 3: Displacements of the buncher and penultimate cavities in $\mathrm{cm}$ and corresponding efficiencies

\begin{tabular}{|l|c|c|c|c|c|}
\hline $\begin{array}{l}\text { Displacement of the } \\
\text { Buncher cavity }\end{array}$ & 0 & +1 & -1 & 0 & 0 \\
\hline $\begin{array}{l}\text { Displacement of the } \\
\text { Penultimate cavity }\end{array}$ & 0 & 0 & 0 & +1 & -1 \\
\hline Efficiency (\%) & 43.2 & 43.0 & 40.7 & 44.2 & 43.4 \\
\hline
\end{tabular}

At the second step, ST was applied to the penultimate and the output cavities for the case of the highest efficiency at the previous step. The results are shown in Table 4. By small changes in their dimensions, the penultimate and the output cavities resonant frequencies were slightly modified. This leads to an essential efficiency increase - from $44.2 \%$ before ST to $45.6 \%$ after ST.

Table 4: Cold-cavity frequencies (in GHz) and efficiency without and with stagger tuning.

\begin{tabular}{|c|c|c|c|}
\hline & $\begin{array}{c}\text { Penultimate } \\
\text { cavity }\end{array}$ & $\begin{array}{c}\text { Output } \\
\text { Cavity }\end{array}$ & Efficiency (\%) \\
\hline Without ST & 17.136 & 17.063 & 44.2 \\
\hline With ST & 17.070 & 17.086 & 45.6 \\
\hline
\end{tabular}


The study of the stability of operation performed by using the code QPB [10] shows that the input, the buncher and the penultimate cavities are stable. However, the starting currents (approximately $600 \mathrm{~A}$ ) for the output cavity operating $\mathrm{TE}_{021}$ mode and parasitic $\mathrm{TE}_{131}$ mode are lower than the beam current of $700 \mathrm{~A}$, i.e. the output cavity is not zero-drive stable. Zero-drive stability of the ouput cavity was demonstrated at $\alpha=1.4$. The efficiency decrease to $43.1 \%$ for this $\alpha$-value but is still very high. Since the pitch-ratio can be varied experimentally between approximately 1.0 and 1.5 the dependence of the efficiency on $\alpha$ is also studied (see Fig. 2). It is evident that the efficiency differs by a factor of about 2 for the end values of the examined $\alpha$-range.

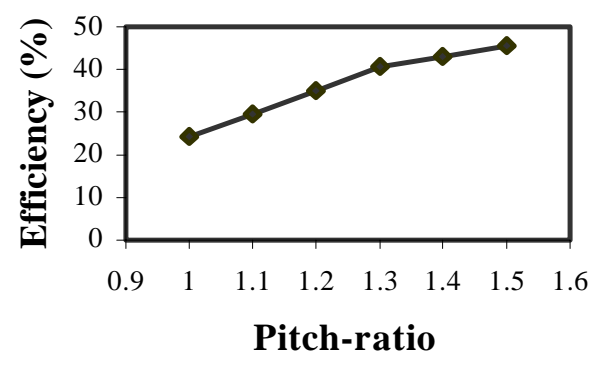

Figure 2: Efficiency dependence on pitch-ratio

\section{CONCLUSION}

A four-cavity coaxial gyroklystron amplifier design for the $17.1 \mathrm{GHz}$ frequency range was presented in this paper. The simulations were performed for a circuit in which the input cavity operates at the fundamental frequency, while the buncher, penultimate and output cavities operate at the second harmonic of the cyclotron frequency (1-2-2-2 circuit). Calculations based on the point-gap model show that this is the most efficient scheme among the schemes with input and output cavities operating at first and second harmonic, respectively.

In order to accelerate the finding of the optimum device parameters with respect to the efficiency and gain a subroutine using the Hooke-Jeeves optimization method was embedded into the large-signal code GYCOAX. Additional optimization of the drift spaces and stagger tuning of the last two cavities were carried out. The simulations predict both very high efficiency and gain of $45.6 \%$ and $71 \mathrm{~dB}$, respectively, for the 1-22-2 gyroklystron, using an electron beam with $500 \mathrm{kV}$ voltage, $700 \mathrm{~A}$ current, perpendicular-to-parallel velocity ratio of 1.5 and parallel velocity spread of $6.4 \%$. Even if we restrict ourselves to a zero-drive stability of the output cavity (at $\alpha \leq 1.4$ ) the efficiency of the studied four-cavity gyroklystron decreases slightly to $43.1 \%$ but it could deliver output microwave power of up to 150 MW.

\section{REFERENCES}

[1] W. Lawson, J. Cheng, J. Calame, M. Castle, B. Hogan, V. Granatstein, M. Reiser, and G. Saraph, "High-Power Operation of a Three-Cavity X-Band Coaxial Gyroklystron", Phys. Rev. Lett., vol. 81, No. 14, pp. 3030-3033 (1998)

[2] G. Saraph, W. Lawson, M. Castle, J. Cheng, J. Calame, and G. Nusinovich, "100-150 MW Designs of Two- and Three-Cavity Gyroklystron Amplifiers Operating at the Fundamental and Second Harmonics in X- and Ku-Bands", IEEE Trans. Plasma Sci., vol.24, No.3, pp. 671-677 (1996)

[3] G. Nusinovich, G. Saraph, and V. Granatstein, "Scaling Law for Ballistic Bunching in Multicavity Harmonic Gyroklystrons", Phys. Rev. Lett., vol. 78, No. 9, pp. 1815-1818 (1997)

[4] J. Neilson, P. Latham, M. Caplan, and W. Lawson, "Determination of the Resonant Frequencies in a Complex Cavity Using the Scattering Matrix Formulation", IEEE Trans. Microwave Theory Tech., vol. 37, No. 8, pp. 1165-1170 (1989)

[5] W. Lawson and P. Latham, "The Scattering Matrix Formulation for Overmoded Coaxial Cavities", IEEE Trans. Microwave Theory Tech., vol. 40, No.10, pp. 1973-1977 (1992)

[6] P. Latham, W. Lawson, and V. Irwin, "The Design of a $100 \mathrm{MW}$, Ku-Band Second Harmonic Gyroklystron Experiment", IEEE Trans. Plasma Sci, vol. 22, No. 5, pp. 804-817 (1994)

[7] B. Bunday in "Basic Optimisation Methods", E. Arnold Publ. Ltd., London (1984), Translated into Russian, pp. 37-42.

[8] G. Nusinovich, B. Danly, and B. Levush, "Gain and Bandwidth in Stagger-Tuned Gyroklystrons", Phys. Plasmas, vol. 4, No. 2, pp. 469-478 (1997)

[9] M. Blank, B. Danly, and B. Levush, "Circuit Design of a Wideband W-Band Gyroklystron Amplifier for Radar Applications", IEEE Trans. Plasma Sci., vol. 26, No. 3, pp. 426-432 (1998)

[10] P. Latham, S Miller, and C. Striffler, "Use of Lie Transforms to Generalize Madey's Theorem for Computing the Gain in Microwave Devices”, Phys. Rev. A, vol. 45, No. 2, pp. 1197-1206 (1992) 